\title{
Vortices of the Mediterranean Sea: An Altimetric Perspective
}

\author{
Jordi IsERn-Fontanet, EmiLio García-LAdOnA, AND Jordi FonT \\ Institut de Ciències del Mar (CSIC), Barcelona, Spain
}

(Manuscript received 16 July 2004, in final form 8 June 2005)

\begin{abstract}
The presence of coherent vortices makes observed mesoscale fields of the ocean resemble twodimensional turbulence. Using this analogy, a common definition of a coherent structure has been used to study the statistical properties of Mediterranean Sea vortices observed by satellite altimeters over a 7-yr period. A vortex has been defined as the simply connected region with values of the Okubo-Weiss parameter $W<-0.2 \sigma_{W}$, where $\sigma_{W}$ is the spatial standard deviation of $W$, and the same sign of vorticity. This definition is shown to be appropriate to detect and characterize, statistically, properties such as size, mean kinetic energy, and amplitude of vortices in the Mediterranean basin from sea level anomaly maps corresponding to the period from October 1992 to October 1999. The distribution of such properties for the Mediterranean vortices suggests a heuristic criterion to extract and select very coherent and long-lived vortices from the whole set of structures identified in altimetric maps. Such coherent vortices appear to be selected for amplitudes greater than $2 \sigma_{W}$, where the amplitude has been defined in terms of the OkuboWeiss parameter rather than vorticity, and strongly correspond to those reported from observations with independent data. Systematic locating and tracking of such vortices provide, for the first time, a general picture of their preferential paths in the Mediterranean basin, which are characterized by complex but rather well defined patterns.
\end{abstract}

\section{Introduction}

Satellite observations of the upper ocean have revealed the ubiquitous presence of nearly horizontal coherent vortices. In general, they are known to play a key role in ocean dynamics because of their effectiveness in moving energy and matter through the ocean and their impact on mixing (see, e.g., Armi et al. 1989; Olson 1991). A detailed characterization of their properties, their spatial distribution, and temporal evolution is very important because vortices modify the statistics of oceanic flows having a great impact on modeling the dispersion and diffusion in the ocean (Davis 1987; Provenzale 1999; Bracco et al. 2000a; Pasquero et al. 2001). The size of these vortices, as well as their energy, varies from one place to another depending on several factors such as latitude, water stratification, bottom topography, or the nature of their generation. These

Corresponding author address: Jordi Isern-Fontanet, Physical Oceanography Group, Institut de Ciències del Mar, CMIMA (CSIC), Passeig Marítim de la Barceloneta, 37-49, E-08003 Barcelona, Spain.

E-mail: jisern@cmima.csic.es properties can be characterized through the construction of a vortex census that is then used to estimate their statistics. Several of such vortex censuses have been built in different parts of the World Ocean from observations of infrared imagery (Brown et al. 1986; Lentini et al. 2002), a combination of climatological in situ data and satellite altimetry (Goni and Johns 2001), or general circulation models (Chassignet 1992).

In the Mediterranean Sea, while there exists a wide literature on observational evidences of vortices, most of the studies on the general circulation have been more focused on Eulerian statistics rather than on coherent vortices (Iudicone et al. 1998; García-Gorriz and Vázquez-Cuervo 1999; Larnicol et al. 2002). The Mediterranean Sea is a semienclosed basin (Fig. 1) with an excess of evaporation mainly compensated by the entrance of relatively fresh waters from the Atlantic Ocean through the Strait of Gibraltar (Fig. 2). The instability of the inflow and local wind action often generate coherent vortices in several parts of the basin. Their effect on the distribution of mean properties is clearly seen in the Algerian Basin $\left(36^{\circ}-40^{\circ} \mathrm{N}, 2^{\circ}-10^{\circ} \mathrm{W}\right)$ where vortices redistribute water masses and produce meridionally smoothed gradients of mean temperature 

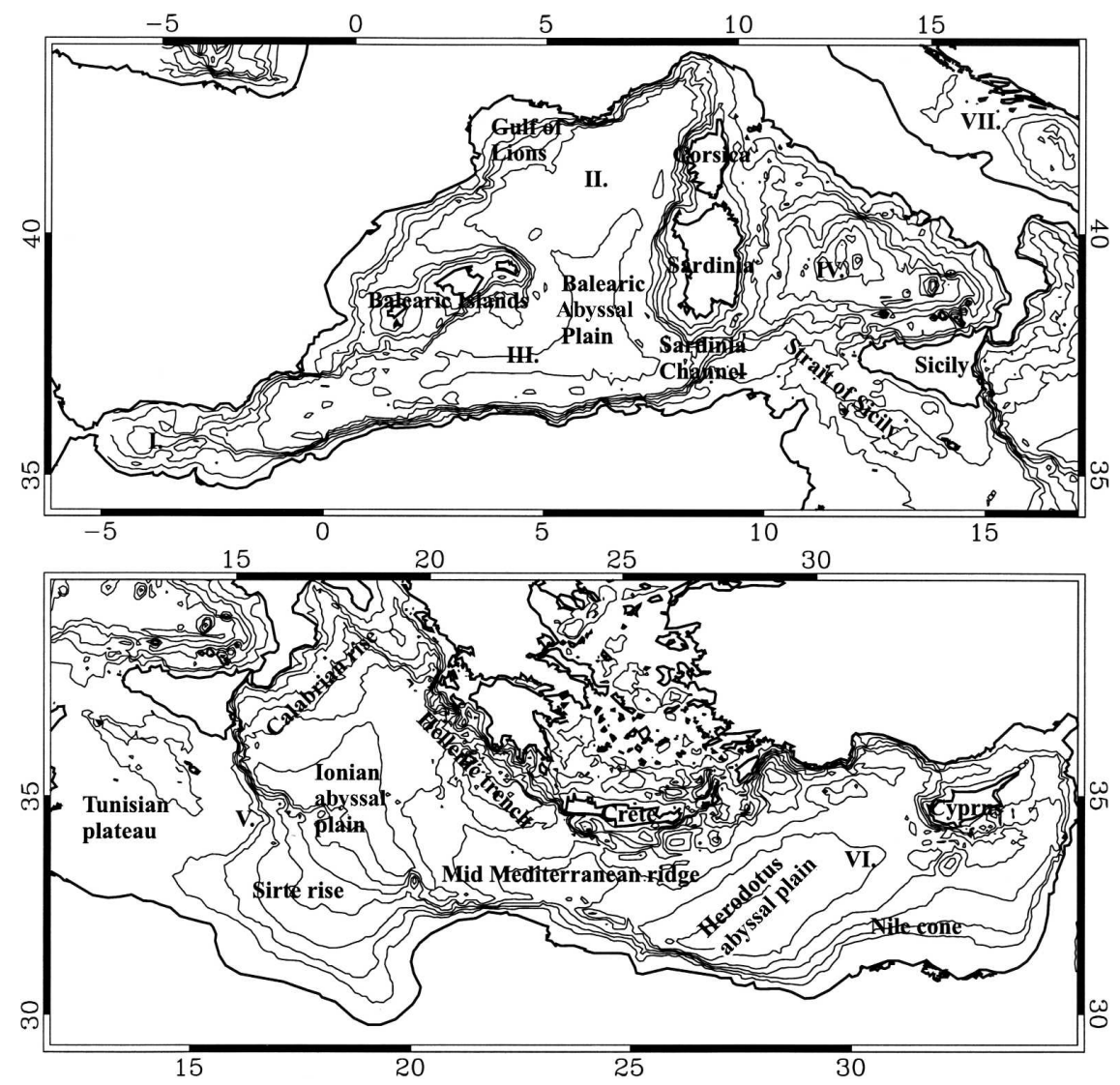

FIG. 1. Bathimetry of the Mediterranean Sea. Roman numerals identify different basins: Alboran Sea (I), Liguro-Provençal Basin (II), Algerian Basin (III), Tyrrenian Sea (IV), Ionian Basin (V), and Levantine Basin (VI).

and salinity toward the central part of the Algerian Basin (Picco 1990; Brasseur et al. 1996; Isern-Fontanet et al. 2004). Despite the advances in the understanding of the dynamics of the Mediterranean Sea over the last 20 years (i.e., Millot 1987, 1999; Malanotte-Rizzoli and Robinson 1994; LaViolette 1995) the detailed behavior of Mediterranean vortices is still poorly known. Instead, a general picture of their distribution and properties can only be recovered from relatively recent and sparse studies.

Starting from the western part, close to the Strait of Gibraltar, one finds the Alboran vortices: two large anticyclones with centers located approximately at $36^{\circ} \mathrm{N}$, $4^{\circ} \mathrm{W}$ and $36^{\circ} \mathrm{N}, 2^{\circ} \mathrm{W}$ (Vazquez-Cuervo et al. 1996; Viúdez et al. 1996). They sometimes have been observed to be accompanied by a third vortex to the east (Parada and Cantón 1998). East of the Alboran Sea, in the Algerian Basin, coastal vortices are formed by the instability of the flow of Atlantic waters that often propagate downstream until the entrance of the Sardinia Channel. There, they are forced to move seaward or they may disappear (Millot 1999). Recent observations have suggested that some of these open-sea vortices may follow an anticlockwise circuit in the easternmost part of the Algerian Basin (Fuda et al. 2000; Puillat et al. 2002; Salas et al. 2002). A similar situation is found in the Liguro-Provençal Basin, in the northwestern part of the Western Mediterranean. Strong northerly winds and a permanent frontal current, mainly due to the salinity contrast between coastal and open-sea waters, are a source of vortices that are smaller when compared with those in the Algerian Basin (Flexas et al. 2002). An exception was a large anticyclone observed during winter 1999 in the Catalan Sea $\left(40.5^{\circ} \mathrm{N}, 3^{\circ} \mathrm{E}\right)$ (Pascual et al. 2001). In the eastern Mediterranean, several vortices surrounding the mid-Mediterranean jet can be found with a nomenclature coined after the Physical Oceanography of the Eastern Mediterranean cruises (Robinson and Golnaraghi 1994): the Pelops anticyclone $\left(36^{\circ} \mathrm{N}, 21^{\circ} \mathrm{E}\right)$, the Cretan cyclone (southwest of Crete, $34^{\circ} \mathrm{N}, 23^{\circ} \mathrm{E}$ ), the Ierapetra anticyclone (southeast of Crete, $34^{\circ} \mathrm{N}, 27^{\circ} \mathrm{E}$ ), the Rhodes cyclone $\left(35^{\circ} \mathrm{N}, 28^{\circ} \mathrm{E}\right)$, West Cyprus cyclone $\left(36^{\circ} \mathrm{N}, 32^{\circ} \mathrm{E}\right)$, Shikmona cyclone (south of Cyprus, $33.5^{\circ} \mathrm{N}, 28^{\circ} \mathrm{E}$ ), and 

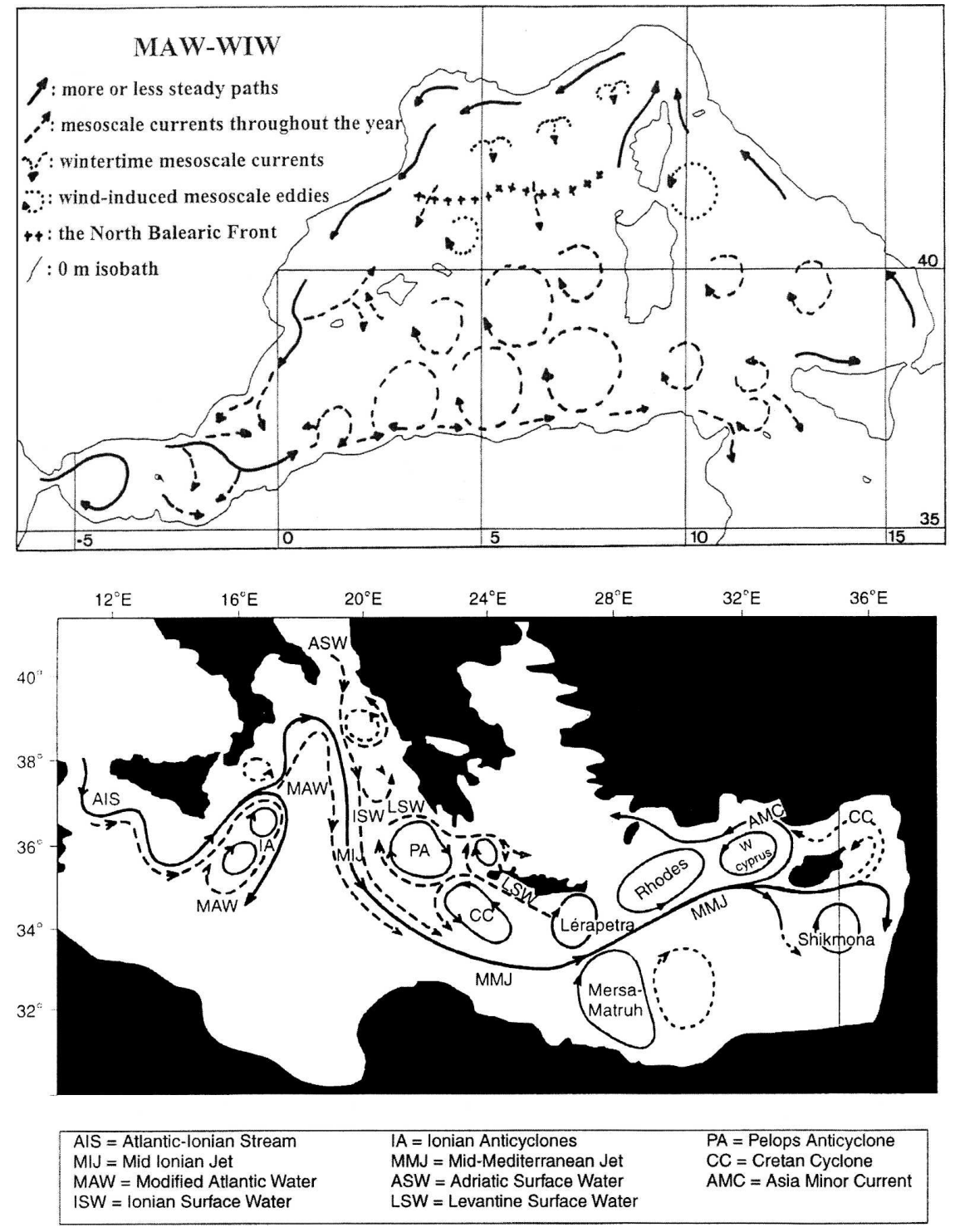

FIG. 2. (top) Surface circulation in the western Mediterranean Sea (Millot 1987). (bottom) Surface circulation in the eastern Mediterranean Sea (Robinson and Golnaraghi 1994).

Mersa-Matruh $\left(33^{\circ} \mathrm{N}, 28^{\circ} \mathrm{E}\right)$. The names given to such structures come from the fact that most of them have been recurrently observed by in situ observations and therefore are considered as permanent features. However, as more intensive and synoptic observations are available it is evident that they may disappear for some periods of time (Viúdez et al. 1996; Matteoda and Glenn 1996). In particular, Larnicol et al. (2002) have suggested that some patterns identified in the eastern Mediterranean, for example, the Mersa-Matruh gyre, may be meanders of the mid-Mediterranean jet rather than vortices or gyres.

In most parts of the World Ocean, satellites launched for ocean observation have provided an adequate sam- pling rate and resolution to detect and study the dynamics of such marine vortices (Brown et al. 1986; Millot 1987; Hooker et al. 1995, 1997; Matteoda and Glenn 1996). These observations have been mostly provided by infrared images. However, two major drawbacks limit the use of infrared data for general quantitative purposes: the inherent problems associated with the observation system, mainly related to data masking by clouds, and the dynamic restrictions on the use of the sea surface "skin" temperature as a passive tracer (Kelly and Strub 1992). Instead, sea surface height from altimetric data is directly a measure of a dynamic property of the ocean. The combination of several altimeters provides the adequate spatial and temporal reso- 
lutions to reasonably sample marine vortices and straightforwardly estimate the ocean velocity fields (Wilkin and Morrow 1994; Stammer 1997; Ayoub et al. 1998; Goni and Johns 2001; Holland and Mitchum 2001; Larnicol et al. 2002).

For geophysical turbulent flows a description in terms of coherent vortices as relevant dynamical entities cannot be addressed without a suitable definition. Such a definition is far for being trivial and has been the object of many works in the past decade (Holmes et al. 1996; Jeong and Hussain 1995; Siegel and Weiss 1997) and still remains an active subject of research (e.g., Farge et al. 2001; Haller 2005). Most of the studies have arisen in the context of turbulent flows requiring accurate analysis of huge datasets and high-resolution numerical simulations. There the approach to vortices or coherent structures has been based either through a decomposition of the flow in dynamic patterns (Siegel and Weiss 1997; Farge et al. 2001) or through some combination of geometrical and dynamical properties of the flow (Hunt et al. 1988; Chong et al. 1990; Jeong and Hussain 1995; Haller 2005). Following on this way, our objective here is to make an approach to study the Mediterranean circulation in terms of an ensemble of vortical structures. The novelty lies in extracting those vortex structures as individual entities, in contrast to past studies based on Eulerian statistics (Iudicone et al. 1998; García-Gorriz and Vázquez-Cuervo 1999; Larnicol et al. 2002). In two previous papers (Isern-Fontanet et al. 2003, 2004) we demonstrated the applicability of one such technique to extract marine vortices from field data. Here we apply it to get, for the first time, statistical information of the properties, spatial distribution, and trajectories of coherent vortices in the Mediterranean basin from historical altimetric maps.

In the following section we briefly describe the data used. In section 3 we present the main statistical properties of the vortices in the Mediterranean based on a census using the Okubo-Weiss parameter, and a criterion for the extraction of the most intense vortices is proposed. In section 4 a tracking algorithm is applied to determine the preferential trajectories for observed coherent vortices. In section 5 the results obtained are discussed in detail and compared with previous observations made with independent data. At the end a summary and conclusions are presented.

\section{Data}

Given the direct relation between the altimetric data and sea-state dynamics, in this study we have used sea level anomaly (SLA) maps produced by the Collecte Localisation Satellites (CLS) in Toulouse (France), which combine the signal of European Remote Sensing
Satellite (ERS) and Ocean Topography Experiment (TOPEX)/Poseidon altimeters. These maps are processed including the usual corrections (sea state bias, tides, inverse barometer, etc.), and with improved ERS orbits using TOPEX/Poseidon as a reference (Aviso 1996; Le Traon and Ogor 1998). SLA are regularly produced by substracting a 4-yr mean value (1993-96) and, prior to the analysis, data are low-pass filtered using a 35-km median filter and a Lanczos filter with a cutoff wavelength of $42 \mathrm{~km}$ in order to reduce altimetric noise (Larnicol et al. 1995). Data collected actually spread over 7 years, from October 1992 to October 1999, but with a gap between December 1993 and March 1995 due to the 168-day ERS-1 orbit. SLA maps are finally built, every 10 days, using an improved space-time objective analysis method, which takes into account longwavelength errors, on a regular grid of $0.2^{\circ} \times 0.2^{\circ}$ (Le Traon et al. 1998), which leaves a total of 213 SLA maps. Data in the Aegean Sea were not considered because of the high density of islands.

Velocities can be estimated, as usual, assuming a geostrophic relationship:

$$
u=-\frac{g}{f} \frac{\partial h^{\prime}}{\partial y} \quad \text { and } \quad v=\frac{g}{f} \frac{\partial h^{\prime}}{\partial x},
$$

where $h^{\prime}$ is the sea level anomaly, $g$ is gravity, and $f$ is the Coriolis parameter.

\section{A census of vortices}

\section{a. Identification of vortices}

The quasi-bidimensional nature of the ocean flows together with the view, as seen in satellite images, of an ocean surface populated by mesoscale structures leads one to consider the two-dimensional and geostrophic turbulence theories as a paradigm for understanding the ocean dynamics (e.g., Rhines 1979; Salmon 1998). Numerical experiments of two-dimensional turbulence have shown that vortices emerge under a wide range of initial conditions if forcing and dissipation are sufficiently small (McWilliams 1984). In this context, some studies have been devoted to the characterization of these vortices by means of an automated vortex census (McWilliams 1990; McWilliams and Weiss 1994; McWilliams et al. 1999) where a key point is a robust vortex-identification criterion. Some of these criteria are based on the relative dominance between strain and deformation in the flow, which can be formulated from different quantities such as the kinematic vorticity number (Truesdell 1953) or the velocity gradient tensor (Hunt et al. 1988; Chong et al. 1990). Jeong and Hussain (1995) have proposed a general criterion based on 
the eigenvalues of a tensor built from the symmetric and antisymmetric decomposition of the velocity gradient tensor. Although they have shown in detail that, when compared with other approaches, it does not capture exactly the same region for general threedimensional flows, all these criteria are equivalent for two-dimensional flows where they reduce to the Okubo-Weiss parameter (Okubo 1970; Weiss 1991), widely used in studies of two-dimensional turbulence (e.g., Jiménez 1996; Pasquero et al. 2001). This parameter is defined as

$$
W=s_{n}^{2}+s_{s}^{2}-\omega^{2},
$$

where $s_{n}=\partial_{x} u-\partial_{y} v$ and $s_{s}=\partial_{x} v+\partial_{y} u$ are the normal and shear components of strain, and $\omega=\partial_{x} v-\partial_{y} u$ is the relative vorticity. Then it provides information about the relative dominance of strain and vorticity and, as revealed in the analysis of numerical simulations, the topology of the velocity field can be partitioned into three regions according to the values of the Okubo-Weiss parameter (McWilliams 1984; Elhmaïdi et al. 1993): elliptic regions $\left(W<-W_{0}\right)$, hyperbolic regions $\left(W>W_{0}\right)$, and a background field $\left(|W| \leq W_{0}\right)$ where $W_{0}$ is a small threshold magnitude (see, e.g., Jiménez 1996; Pasquero et al. 2001).

Since vortices are single connected regions of concentrated vorticity in which there is a dominance of vorticity over strain, the Okubo-Weiss parameter offers a basis for a vortex identification criterion as a region with negative values of $W$. More precisely, results suggest a definition of a vortex as a region with values of the Okubo-Weiss $(W)$ parameter smaller in magnitude than a threshold $W_{0}=0.2 \sigma_{W}, \sigma_{W}$ being the spatial standard deviation of $W$ and having the same sign of vorticity. Although the flow partition given by the Okubo-Weiss parameter has been shown that it may be inaccurate (Basdevant and Philipovitch 1994) and that a more refined and exact condition has been recently proposed (Hua and Klein 1998), it is still valid to characterize vortex core regions or saddle points. This vortex identification criterion has been tested to successfully identify marine vortices from SLA maps (Isern-Fontanet et al. 2003; Morrow et al. 2004) and to analyze drifter data (Stocker and Imberger 2003; Testor and Gascard 2004).

\section{b. Vortex properties}

Spatial distributions of the Okubo-Weiss parameter, as given by Eq. (2), have been computed using the velocity field derived from SLA maps computed from Eq. (1). After a vortex is identified, its properties can be calculated. We have focused on three properties: vortex size, amplitude, and kinetic energy.
Vortex core size $(A)$ is given by the number of simply connected grid points $\left(N_{\mathrm{gp}}\right)$ with $W \leq-0.2 \sigma_{W}$ having the same sign of vorticity

$$
A \equiv N_{\mathrm{gp}}
$$

This magnitude may be hard to interpret and difficult to compare with other studies with different grids. For this reason an equivalent radius $\left(r_{e}\right)$ is defined that corresponds to the radius of an equivalent circular vortex with the same area

$$
r_{e} \equiv R_{T} \sqrt{\frac{N_{\mathrm{gp}}}{\pi} \Delta \phi \Delta \lambda \cos \phi_{0}},
$$

where $R_{T}$ is the mean earth radius, $\phi_{0}=38^{\circ} \mathrm{N}$ is the reference latitude, and $\Delta \phi=\Delta \lambda=0.2^{\circ}$ is the grid spacing. Here the area associated with a single grid point at the reference latitude is $390 \mathrm{~km}^{2}$ and its equivalent radius is $\sim 11 \mathrm{~km}$.

Vortex amplitude $(a)$ is defined as the maximum absolute value of the Okubo-Weiss parameter inside the vortex:

$$
a \equiv \max \left(\left|W_{i}\right|\right), i=1, \ldots, N_{\mathrm{gp}} .
$$

This definition is equivalent to the more common definition of amplitude in terms of vorticity: when $\omega^{2} \gg s_{n}^{2}$ $+s_{s}^{2}$, then $a \simeq \max \left(\omega^{2}\right)$. In practice, for the strongest vortices the use of amplitude or vorticity does not change significantly. However, for weaker vortices embedded in a background field with vorticity there could be significant differences.

Vortex energy $E$ is taken as the spatial average of the kinetic energy over the vortex area

$$
E \equiv \frac{1}{2 N_{\mathrm{gp}}} \sum_{i=1}^{N_{\mathrm{gp}}}\left(u_{i}^{2}+v_{i}^{2}\right)
$$

\section{c. Statistics of vortex properties}

The application of such definitions to the Mediterranean SLA dataset gives a total amount of 20531 anticyclonic and 20959 cyclonic vortices for the whole period (1992-99) with a mean number of vortices per map of about 100 anticyclones and a similar number for cyclones. The spatial distribution of the observed vortices for the whole analyzed period (Fig. 3) shows a relatively homogeneous distribution of structures that fills the whole basin for both cyclonic and anticyclonic structures. The time series of the number of vortices $N_{v}$ shows a seasonal cycle plus some interannual variability; $N_{v}$ is typically a minimum at the beginning of September and maximum around March with a linear correlation coefficient between the number of cyclonic and anticyclonic structures of 0.48 (Fig. 3). 

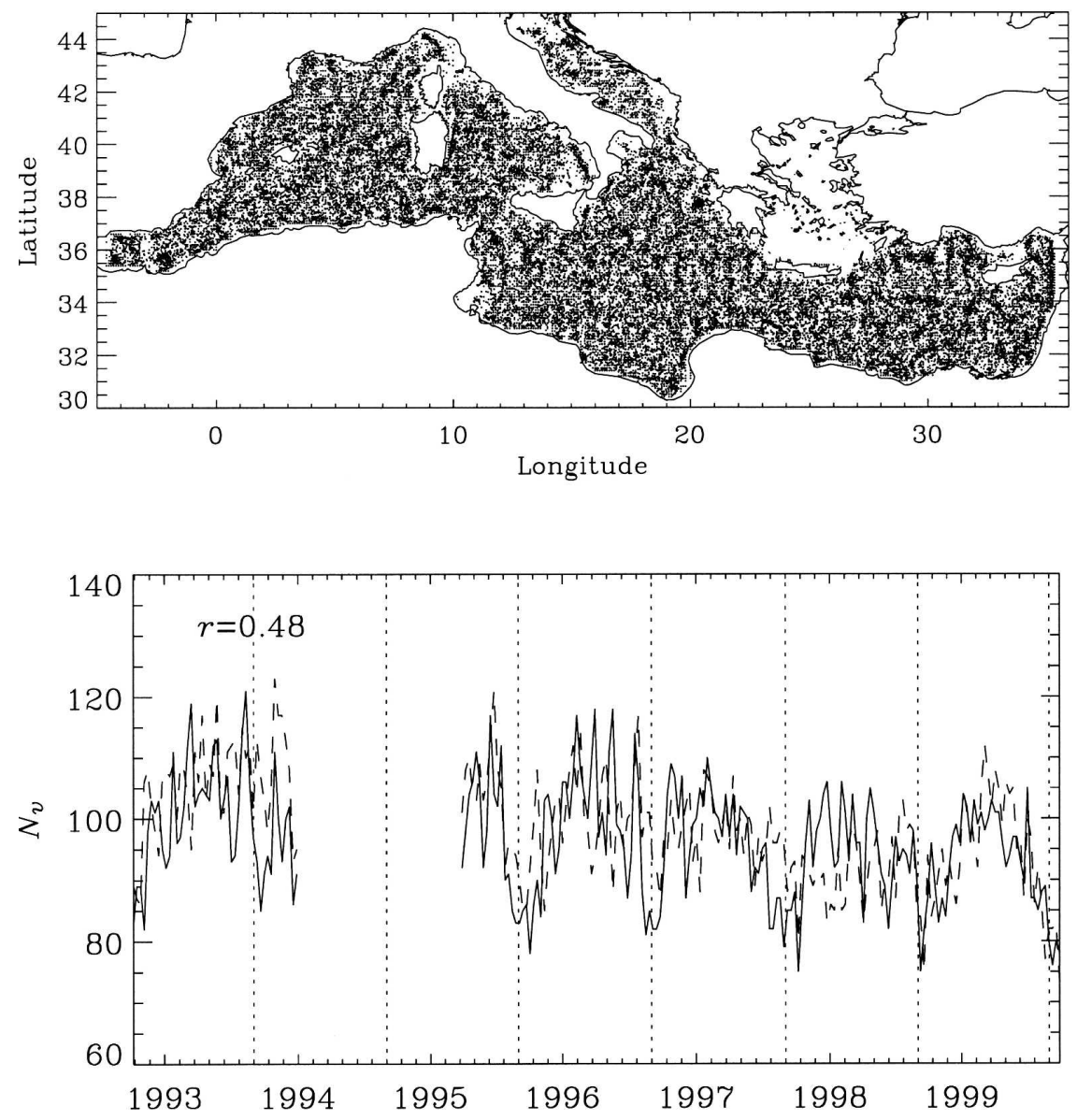

FIG. 3. (top) Spatial distribution of the centers of observed vortices for the period October 1992-October 1999. (bottom) Temporal evolution of the number of cyclonic (dashed line) and anticyclonic (solid line) vortices observed in each map $\left(N_{v}\right)$. The dotted line is drawn for each 1 September.

A detailed counting of structures shows that there are more anticyclonic vortices with high values of amplitude, energy, and size than cyclonic vortices, and, as it is evident by looking to their first moments (Table 1), their mean values and standard deviations are also big-

TABLE 1. Mean $(\langle x\rangle)$, standard deviation $\left(\sigma_{x}\right)$, skewness $\left(s_{x}\right)$, and kurtosis $\left(k_{x}\right)$ of the observed distributions of amplitude $(a)$, energy $(E)$, and size $(A)$ for cyclonic $(+)$ and anticyclonic $(-)$ vortices. Shown in parentheses: the equivalent radius.

\begin{tabular}{cccccc}
\hline \hline \multicolumn{1}{c}{$X$} & $\omega$ & $\langle x\rangle$ & $\sigma_{x}$ & $s_{x}$ & $k_{x}$ \\
\hline$a\left(\sigma_{W}\right)$ & - & 1.6 & 2.3 & 4.6 & 32.0 \\
& + & 1.3 & 1.5 & 3.7 & 23.3 \\
& & & & & \\
$E\left(\mathrm{~cm}^{2} \mathrm{~s}^{-2}\right)$ & - & 54.9 & 75.8 & 5.3 & 49.8 \\
& + & 47.3 & 52.1 & 3.2 & 17.6 \\
& & & & & \\
$A$ & - & $6.9(29 \mathrm{~km})$ & $5.2(25 \mathrm{~km})$ & 1.2 & 1.7 \\
& + & $6.6(29 \mathrm{~km})$ & $4.9(25 \mathrm{~km})$ & 1.2 & 1.9 \\
\hline
\end{tabular}

ger. All distributions of vortex properties have positive values of skewness and are leptokurtic, with higher values for the distributions of energy and amplitude. The definition of kurtosis here used includes a -3 term that makes the value zero for a normal distribution (Press et al. 1994). These values of kurtosis and skewness are significant because they are much bigger than $\sqrt{15 / N_{v}}$ and $\sqrt{96 / N_{v}}$, respectively. The $\chi^{2}$ test shows that distributions of cyclonic and anticyclonic vortices cannot be derived from the same distribution $\left(\chi^{2} \gg 1\right)$.

The relationships between energy and size as functions of amplitude (Fig. 4) are analyzed by considering mean values of energy, $\langle E\rangle_{a}$, and equivalent radius, $\left\langle r_{e}\right\rangle_{a}$, for amplitude bins of size $\Delta a=0.5 \sigma_{W}$. The dependence of $\langle E\rangle_{a}$ on $a$ is rather linear with increasing standard deviation and fluctuations as $a$ grows. The standard deviation ranges from $\sigma_{E} \sim 25 \mathrm{~cm}^{2} \mathrm{~s}^{-2}$ for small values of amplitude to $\sigma_{E} \sim 100 \mathrm{~cm}^{2} \mathrm{~s}^{-2}$ for larger values. The equivalent radius $\left\langle r_{e}\right\rangle_{a}$ has a different behavior: 

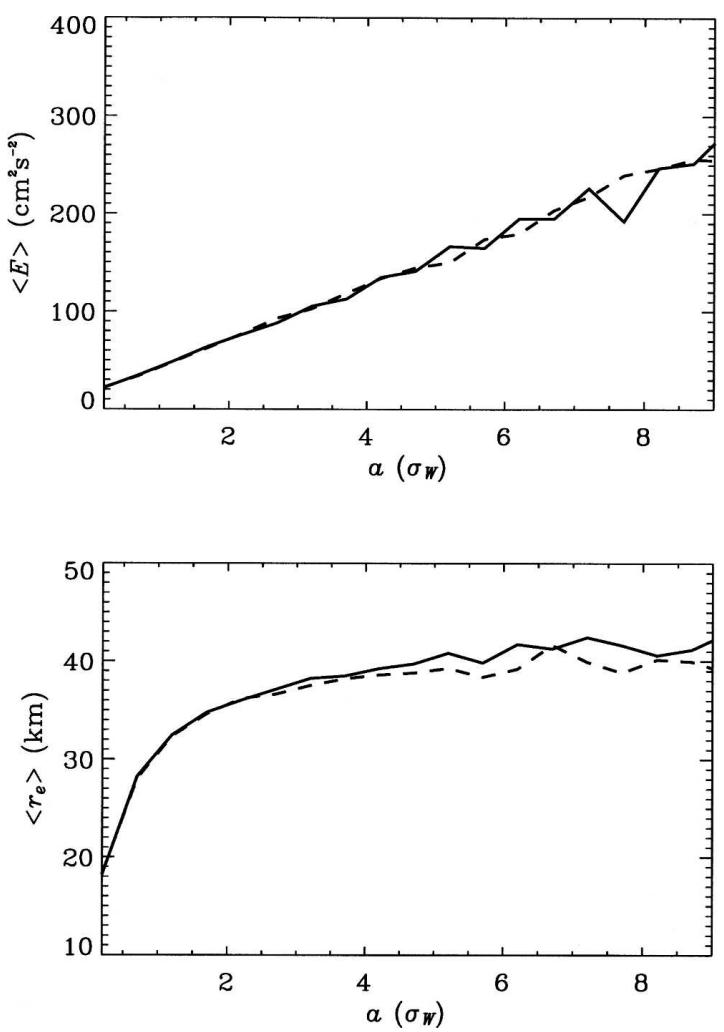

FIG. 4. (top) Dependence of mean energy $\left(\langle E\rangle_{a}\right)$ with amplitude (a). (bottom) Dependence of mean equivalent radius $\left(\left\langle r_{e}\right\rangle_{a}\right)$ with amplitude $(a)$. Solid line corresponds to anticyclone structures $(\omega<0)$, and dashed line corresponds to cyclonic $(\omega<0)$.

it quickly grows with increasing amplitude until an amplitude around $2 \sigma_{W}$, which corresponds to a radius of about $35 \mathrm{~km}$, and then it slowly tends to a saturation value of about $40 \mathrm{~km}$. As before, fluctuations increase

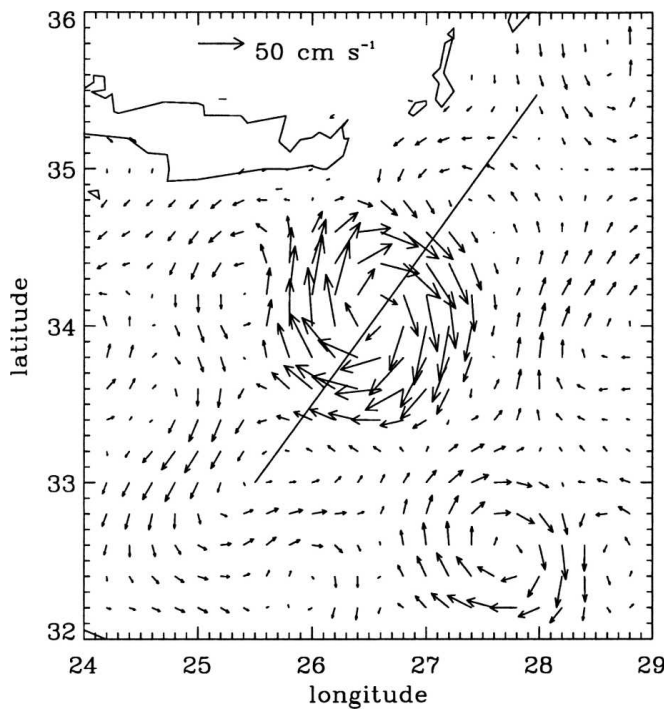

for larger values of $a$, but the standard deviation remains approximately constant $\left(\sigma_{r e} \sim 7 \mathrm{~km}\right)$.

Concerning the census, we should take into account the way a vortex structure is characterized by $W$, which appears closely similar to the structure of two-dimensional turbulence vortices (Isern-Fontanet et al. 2004). Figure 5 shows a profile of $W$ crossing one diameter of the Ierapetra vortex $\left(34^{\circ} \mathrm{N}, 27^{\circ} \mathrm{E}\right)$, which is composed of an inner part, with a radius of about $50 \mathrm{~km}$, characterized by a dominance of vorticity over strain $(W<0)$, surrounded by a region dominated by strain over vorticity $(W>0)$, with radius ranging between 50 and 100 $\mathrm{km}$. Thus, the definition used to build the census only captures the inner part, the core, which approximately corresponds to the region enclosed by the radial location of the maximum of velocity. This implies that the size of vortices is systematically underestimated. Notice that in this example the equivalent radius is of the order of half the radius of the whole vortex. From Fig. 5 it is also clear that a variation on the threshold value should imply a variation in the size of the region captured. The threshold here used is calculated by considering the standard deviation of the instantaneous maps of $W$, selected by analogy with turbulence studies (Jiménez 1996; Bracco et al. 2000b; Pasquero et al. 2001). This value is rather small and does not change significantly the radius of the kind of vortices like the one shown, for example, in Fig. 5.

The first moments of vortex properties (Table 1) show that SLA maps are dominated by small, lowenergy, and low-amplitude structures that are very similar for cyclonic and anticyclonic structures but with a low linear correlation between the number of cyclonic

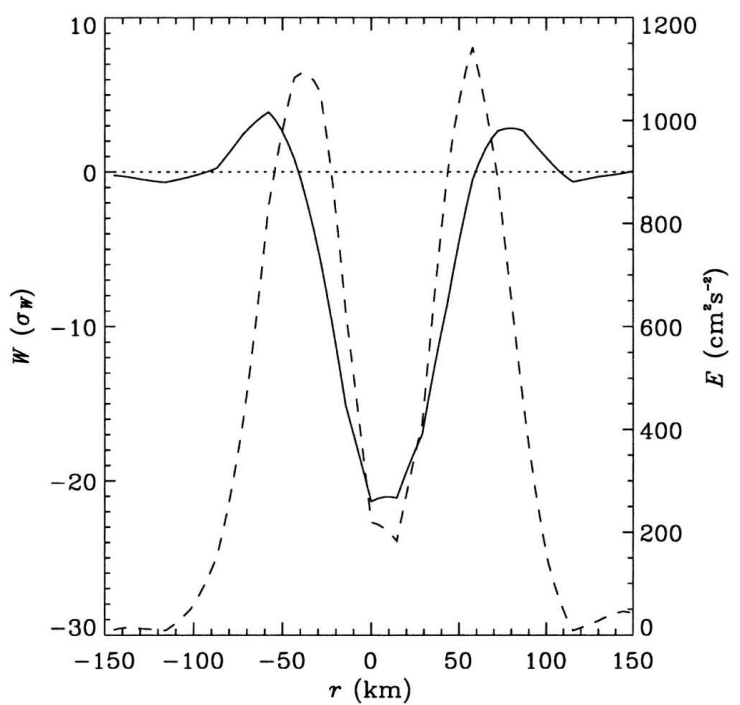

FIG. 5. (left) Geostrophic velocities corresponding to the SLA map of 6 Nov 1992, and (right) $W$ profile (solid line) and energy profile (dashed line) along the diameter of the Ierapetra vortex marked with a solid line $\left(\sigma_{W}=3.58 \mathrm{~s}^{-2}\right)$. 


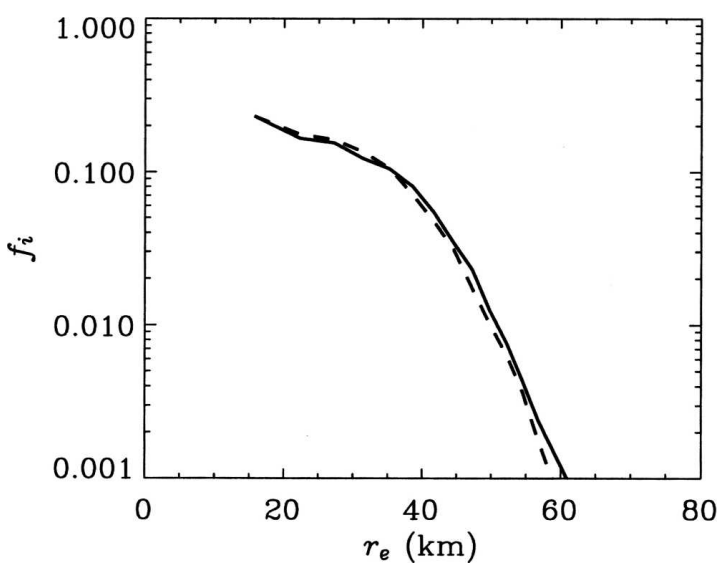

FIG. 6. Observed frequencies for the equivalent radius corresponding to cyclonic (dashed line) and anticyclonic (solid line) vortices.

and anticyclonic vortices. A detailed look to the shape of the distribution of sizes (Fig. 6) shows that the slope of the distribution is smaller for values of $r_{e} \lesssim 40 \mathrm{~km}$, which is approximately the cutoff wavelength used for filtering the along-track altimetric data. This suggests that SLA maps may underestimate the number of small structures. On the other hand, the relation of $\left\langle r_{e}\right\rangle_{a}$ with amplitude shows that for amplitudes bigger than $2 \sigma_{W}$ the mean radius remains more or less constant. On a $\beta$ plane vortex sizes have an upper bound: the Rhines scale, defined as $L_{\beta}=\sqrt{U / \beta}$ where $U$ is a characteristic velocity and $\beta$ the meridional derivative of the Coriolis parameter. In this case, it is on the order of $L_{\beta}=167 \mathrm{~km}$ taking $U=50 \mathrm{~cm} \mathrm{~s}^{-1}$ and a reference latitude of $\phi_{0}=38^{\circ} \mathrm{N}\left(\beta=1.798 \times 10^{-13} \mathrm{~cm}^{-1} \mathrm{~s}^{-1}\right)$. The asymptotic value observed in Fig. 4 is of the order of $\left\langle r_{e}\right\rangle \rightarrow L_{\beta} / 4$. Notice that, as discussed before, the detection algorithm used only identifies the vortex core region.

\section{d. Coherent vortices}

Spatial distribution of average vortex properties is studied by dividing the Mediterranean Sea into bins of $0.25^{\circ} \times 0.25^{\circ}$ and considering those that contain at least five vortex centers per bin. Then, for each bin mean properties have been computed (Fig. 7). Results show a closer correspondence between the distributions of energy and amplitude, but are slightly different with respect to the size distribution: $E$ and $a$ are inhomogeneously distributed while the distribution of sizes is more uniform. High-energy strong amplitude structures are found in those areas where intense variability related to the presence of highly coherent vortices is known to exist. This suggests that such coherent vorti- ces could be extracted from the census by applying a threshold value to their properties. If we look at the plot in Fig. 4, one can observe that amplitude seems to be a good candidate for doing such separation. There appears some kind of saturation for amplitudes greater than $2 \sigma_{W}$ where $\left\langle r_{e}\right\rangle_{a}$ does not grow significantly with amplitude. Then, we have applied this threshold value to classify the structures in the census as

- Intense vortex (coherent vortex): vortex with an amplitude $a>2 \sigma_{W}$.

- Weak vortex: vortex with an amplitude $a \leq 2 \sigma_{W}$.

We could have used energy to select coherent structures with similar results. Indeed, as clearly shown by Fig. 4 the relation of $\langle E\rangle_{a}$ with amplitude is linear, showing that, in general, large amplitude vortices have high values of energy. This is reinforced by comparison of the spatial distribution of $E$ and $a$ (Fig. 7). However, an important difference is that energy is a property that is not invariant under Galilean transformations, which implies that the energy of a vortex embedded in a mean flow contains the contribution of the flow. On the other hand, since the criterion proposed above selects vortices with large mean sizes, an alternative would have been to extract coherent vortices with a threshold over their size. However, in the census over instantaneous SLA maps it has been observed that the existence of large areas with small values of energy and amplitude do not correspond to coherent structures but, rather, to large recirculation gyres.

The application of the above criterion allows us to identify a total of $4642(53 \%)$ anticyclonic and 4173 (47\%) cyclonic intense vortices with around 20 anticyclonic and cyclonic vortices per map. As expected, their spatial distribution is inhomogeneous with highest concentration of vortices in those regions where highest values of energy or amplitude were found (Fig. 8). Among these regions there are clearly identifiable centers of the Alboran vortices and the Ierapetra vortex. In contrast to the total number of structures given initially in this case, the temporal evolution of the number of coherent vortices does not exhibit any marked seasonality (not shown). Also, first moments of vortex properties show that anticyclonic vortices are bigger and more energetic than cyclonic (Table 2). The number of remaining structures (weak vortices) is 4 times larger than for intense vortices. They are smaller and less energetic than intense vortices and are more or less uniformly distributed in the Mediterranean Sea except in those regions with a high concentration of intense vortices (e.g., the easternmost part of the Algerian Basin, $36^{\circ}-40^{\circ} \mathrm{N}, 4^{\circ}-10^{\circ} \mathrm{E}$; not shown). 

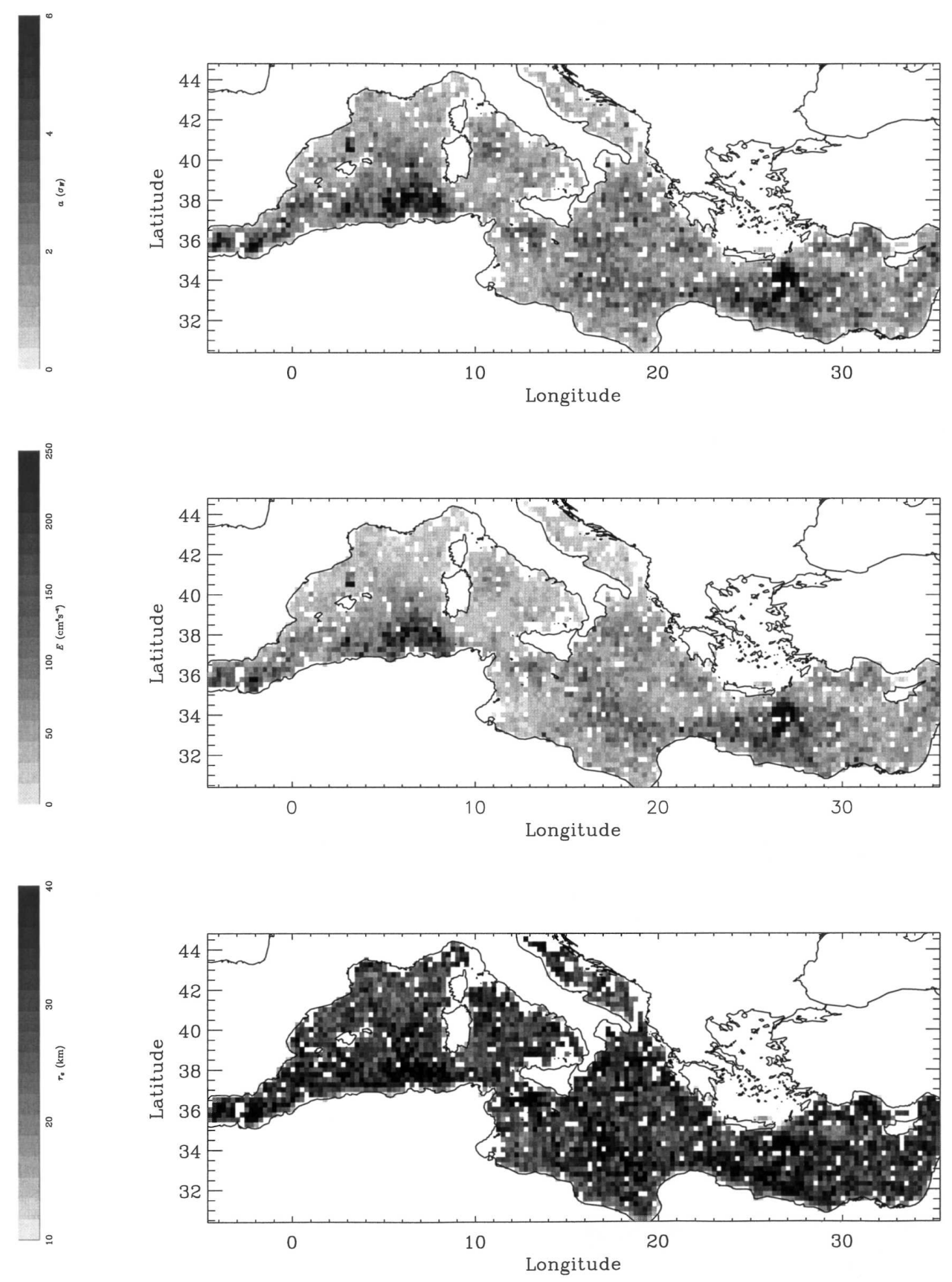

FIG. 7. Spatial distribution of (top) vortex amplitude $(a)$, (middle) energy $(E)$, and (bottom) equivalent radius $\left(r_{e}\right)$.

\section{Vortex trajectories}

In the previous section intense vortices have been defined and identified so that they can be automatically located and tracked from map to map to obtain their trajectories. Two intense vortices in two consecutive maps are considered the same one if the geometrical distance between both is the smallest distance between any other possible pair of the same maps. However, situations in which a vortex may appear, disappear, or split or two vortices can merge to a single one should be taken into account. This is done by introducing two additional parameters $\lambda_{1}$ and $\lambda_{2}$. Here $\lambda_{1}$ represents the upper-bound distance that a vortex can travel in one time step, which is taken as $\lambda_{1}=c_{\max } \Delta t$ considering that $c_{\max }=10 \mathrm{~km}$ day $^{-1}$ and $\Delta t=10$ days. Then, if the 


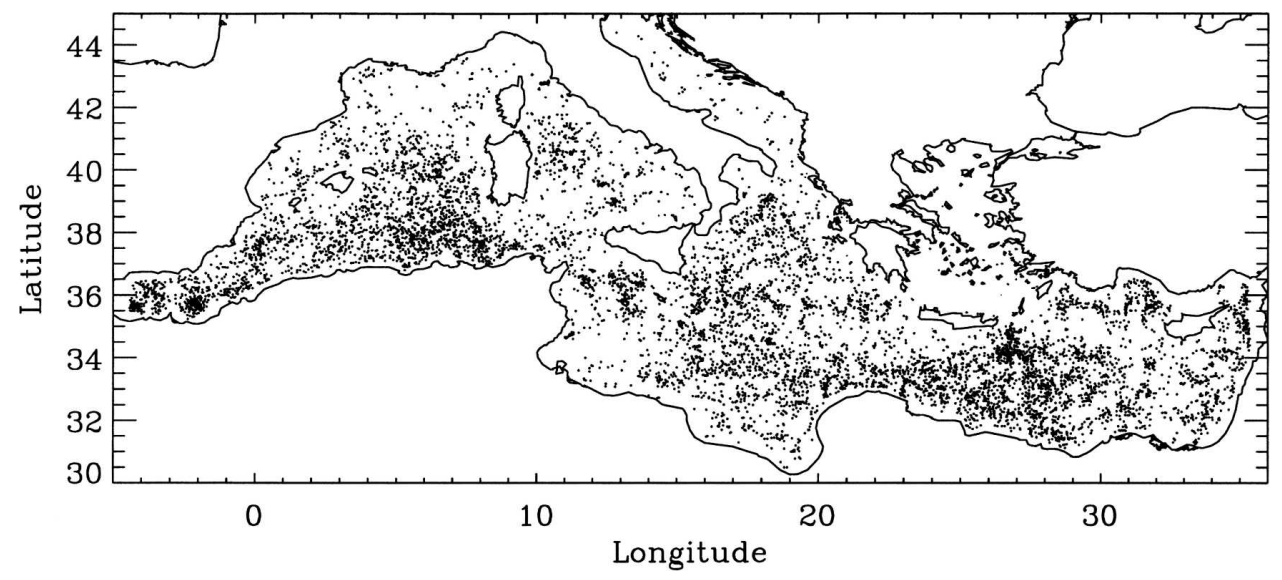

FIG. 8. Spatial distribution of the centers of observed intense vortices $\left(a>2 \sigma_{W}\right)$ for the period October 1992-October 1999.

distance between two vortices in consecutive maps is greater than $\lambda_{1}$, these two vortices are not considered the same vortex. The second parameter, $\lambda_{2}$, allows one to make decisions in situations where vortices merge or split. It is considered as the minimum distance difference allowed between two pairs of vortex distances and it is taken to be of the order of $\lambda_{2}=20 \mathrm{~km}$, which approximately corresponds to one-half of the mean radius of intense vortices. Then, when a vortex identified in one map is closely located to several vortices in the consecutive (previous) map, a vortex is considered to be split (merged) if the differences between each pair are smaller than $\lambda_{2}$.

The algorithm provides a total of 452 trajectories of anticyclonic intense vortices (Fig. 9) and 447 of cyclonic intense vortices (Fig. 10) composed of at least three time points. Observed mean lifetimes are nearly 2 months for anticyclonic vortices with 73 trajectories longer than 90 days, with a maximum of 790 days. Cyclonic vortices have mean lifetimes of the order of 1 month with 31 trajectories longer than 90 days and a maximum of 240 (see Table 3). These values have to be considered as a lower bound since the selection of $\lambda_{1}$ and $\lambda_{2}$ is done in order to reduce the

TABLE 2. Mean $(\langle x\rangle)$, standard deviation $\left(\sigma_{x}\right)$, skewness $\left(s_{x}\right)$, and kurtosis $\left(k_{x}\right)$ of the observed distributions of energy $(E)$ and size $(A)$ for intense $\left(a>2 \sigma_{W}\right)$ cyclonic $(+)$ and anticyclonic $(-)$ vortices. Shown in parentheses is the equivalent radius.

\begin{tabular}{cccccr}
\hline \hline \multirow{2}{*}{$X$} & $\omega$ & $\langle x\rangle$ & $\sigma_{x}$ & $s_{x}$ & \multicolumn{1}{c}{$k_{x}$} \\
\hline$E\left(\mathrm{~cm}^{2} \mathrm{~s}^{-2}\right)$ & - & 138.2 & 121.0 & 3.7 & 21.8 \\
& + & 113.2 & 71.3 & 2.1 & 6.7 \\
& & & & & \\
$A$ & - & $12.4(39 \mathrm{~km})$ & $4.8(25 \mathrm{~km})$ & 1.1 & 2.5 \\
& + & $11.7(38 \mathrm{~km})$ & $4.5(24 \mathrm{~km})$ & 1.0 & 2.0 \\
\hline
\end{tabular}

incorrect tracking of vortices. Unfortunately this may break some trajectories into smaller pieces. Propagation velocities are of the order of $2 \mathrm{~km} \mathrm{day}^{-1}$ and mean paths of the order of $100 \mathrm{~km}$ for anticyclonic and $78 \mathrm{~km}$ for cyclonic. When compared with similar studies in other parts of the ocean, the range of propagation velocities is very different (i.e., Meyers and Basu 1999; Andrade and Barton 2000; Lentini et al. 2002). The propagation velocities are smaller relative to Agulhas rings $\left(C \sim 5 \mathrm{~km} \mathrm{day}^{-1}\right.$ : Schouten et al. 2000) or vortices in the region of the Brazil Current $\left(C \sim 10 \mathrm{~km} \mathrm{day}^{-1}\right.$ or larger: Lentini et al. 2002). The semienclosed character of the Mediterranean basin with the absence of very strong permanent currents prevents the eddies from propagating faster, being confined by boundaries and bottom topography and favoring close interactions among them.

The tracking of vortices has been validated in different ways. Trajectories for some vortices were compared and validated with previously reported paths inferred from temporal sequences of infrared imagery and drifting buoy trajectories (Isern-Fontanet et al. 2003; Font et al. 2004), showing good agreement. In addition, trajectories in some regions (e.g., the Algerian Basin: $36^{\circ}-$ $40^{\circ} \mathrm{N}, 2^{\circ} \mathrm{W}-10^{\circ} \mathrm{E}$ ) have been compared with those obtained from visual inspection of sequential maps of the Okubo-Weiss parameter. The comparison of trajectories obtained with these two methods showed that both sets of trajectories presented similar patterns (not shown). Last, the complete set of the 213 maps of the Okubo-Weiss parameter for the whole basin, with vortices labeled automatically as described before, has been visually inspected, showing that there were few errors in the trajectories obtained with the automatic method. 


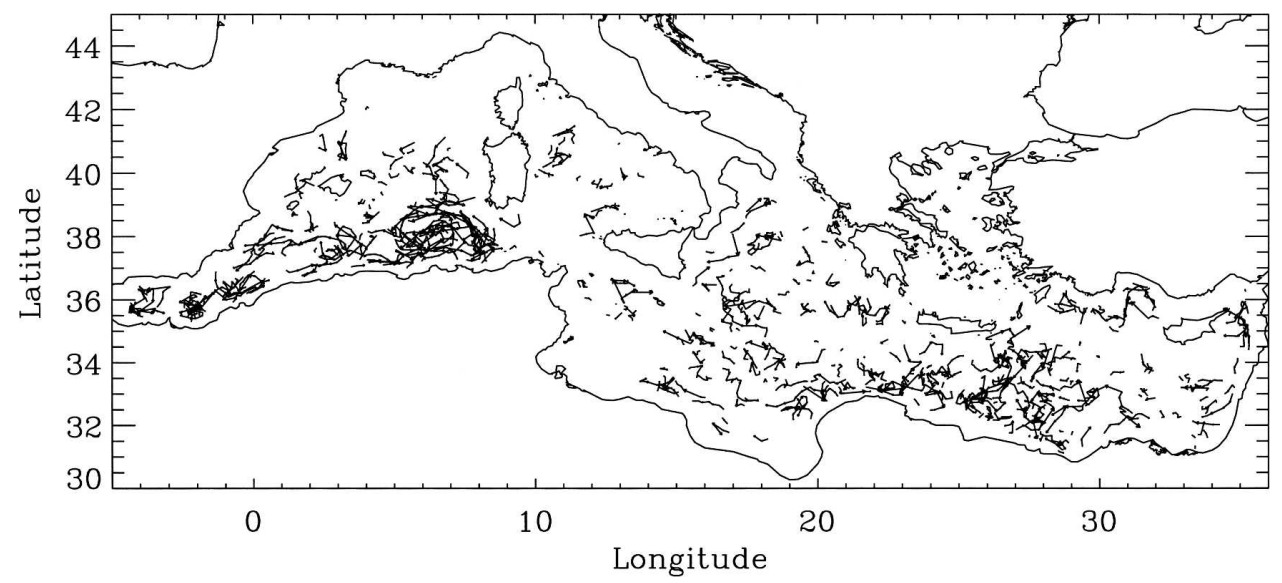

FIG. 9. Observed trajectories of intense anticyclonic vortices for the period October 1992-September 1999.

\section{Discussion}

The application of the Okubo-Weiss criterion has shown a basin full of vortices. The heuristic classification derived from their statistical properties has the classification into intense and weak vortices; however, many questions arise around the results found in previous sections.

A first aspect is to what extent the criterion here used to extract coherent structures is consistent with other observations. The spatial distribution of statistical properties of coherent vortices has revealed regions where they are more energetic and have greater sizes and amplitude values (Fig. 7). This is particularly clear in regions characterized by the presence of recurrent vortices as in the Alboran Sea, with two well-identified areas $\left(36^{\circ} \mathrm{N}, 4^{\circ} \mathrm{W}\right.$ and $\left.36^{\circ} \mathrm{N}, 2^{\circ} \mathrm{W}\right)$, the singular longlived vortex observed in the Catalan Sea during winter $1999\left(40.5^{\circ} \mathrm{N}, 3^{\circ} \mathrm{E}\right)$, or the Ierapetra vortex $\left(34^{\circ} \mathrm{N}\right.$, $27^{\circ} \mathrm{E}$ ) south of Crete in the Levantine Basin. Highest values are also found in wide regions, as in the southern part of the Algerian Basin $\left(36^{\circ}-40^{\circ} \mathrm{N}, 5^{\circ}-9^{\circ} \mathrm{E}\right)$. More moderate values can be found in other regions such the Tyrrenian Sea (east of Sardinia: $40.5^{\circ} \mathrm{N}, 10^{\circ}-11^{\circ} \mathrm{E}$ ), in the Ionian Basin parallel to the continental slope [from Sicily $\left(38^{\circ} \mathrm{N}, 16^{\circ} \mathrm{E}\right)$ to the eastern part of the Lybian coast $\left.\left(32^{\circ} \mathrm{N}, 20^{\circ} \mathrm{E}\right)\right]$, south of the Anatolian peninsula (west of Cyprus: $36^{\circ} \mathrm{N}, 28-32^{\circ} \mathrm{E}$ ). This suggests that a relatively important fraction of the energy should be contained in those structures. If the Eulerian eddy kinetic energy (EKE) is computed from the complete time series of velocity fields (Fig. 11), it can be observed that the regions with high EKE content strongly correlate with the regions occupied by intense vortices. Equivalently, these also correspond to regions of high sea level variance (see Fig. 2 in Larnicol et al. 2002).

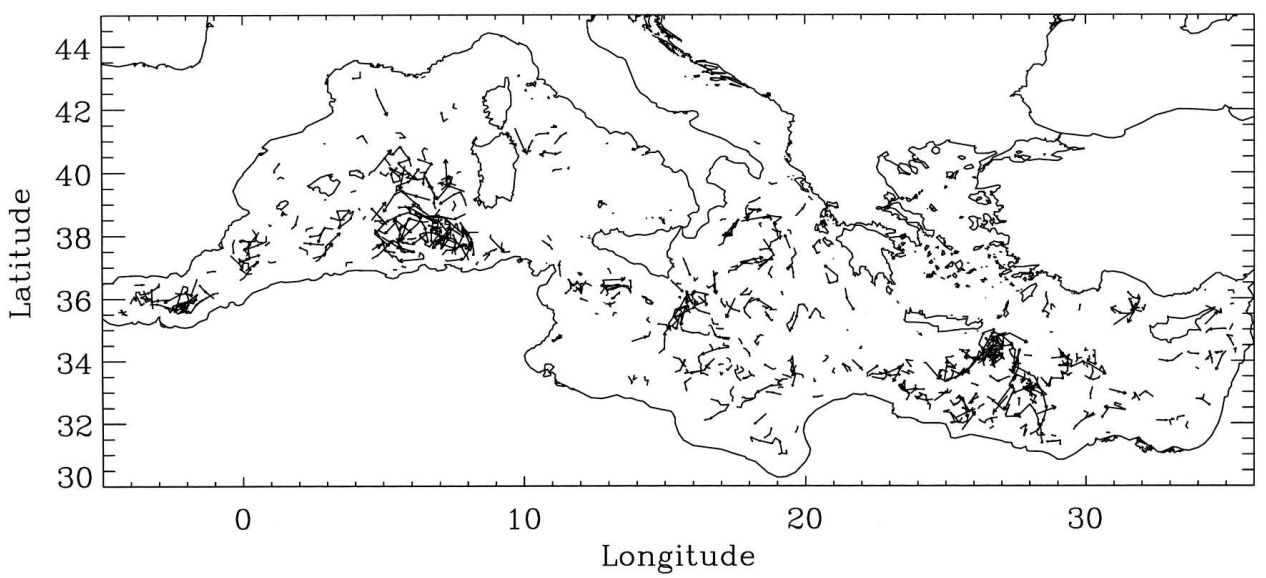

FIG. 10. Observed trajectories of intense cyclonic vortices for the period October 1992-September 1999. 
TABLE 3. Mean $(\langle x\rangle)$, standard deviation $\left(\sigma_{x}\right)$, skewness $\left(s_{x}\right)$, and kurtosis $\left(k_{x}\right)$ of the observed distributions of lifetime $(T)$, trajectory length $(L)$, and propagation velocity $(C)$ for cyclonic $(+)$ and anticyclonic $(-)$ intense vortices.

\begin{tabular}{lccccc}
\hline \hline \multicolumn{1}{c}{$x$} & $\omega$ & $\langle x\rangle$ & $\sigma_{x}$ & $s_{x}$ & $k_{x}$ \\
\hline$T\left(\right.$ day $\left.^{-1}\right)$ & - & 54.0 & 60.4 & 5.8 & 54.7 \\
& + & 38.8 & 31.4 & 3.0 & 11.1 \\
$L(\mathrm{~km})$ & - & 100 & 127 & 7.4 & 91.0 \\
& + & 78.1 & 75.2 & 2.7 & 10.2 \\
& & & & & \\
& - & 1.9 & 1.5 & 1.8 & 4.0 \\
& + & 2.0 & 1.7 & 1.7 & 3.2 \\
\hline
\end{tabular}

Concerning the trajectories of anticyclonic coherent vortices (Fig. 9), in the Alboran Sea $\left(5^{\circ}-2^{\circ} \mathrm{W}\right)$ it can be observed that trajectories tend to be concentrated around two points located at $35.75^{\circ} \mathrm{N}, 4^{\circ} \mathrm{W}$ and $35.75^{\circ} \mathrm{N}, 2^{\circ} \mathrm{W}$. Near the Spanish coast is another set of trajectories that may indicate the presence of a vortex. East of the Alboran Sea, along the African coast $\left(0^{\circ}-\right.$ $\left.1^{\circ} \mathrm{E}\right)$, there is a set of trajectories that indicates the presence of a large vortex close to the coast. In the Algerian Basin $\left(36^{\circ}-40^{\circ} \mathrm{N}, 2^{\circ} \mathrm{W}-10^{\circ} \mathrm{E}\right)$ vortices are observed to propagate eastward along the coast. Three vortices were observed to detach from the coast near $4^{\circ} \mathrm{E}$ and two of them began to propagate toward the west, south of the Balearic Islands. The third one propagated toward the west until, some weeks later, it returned to the Algerian coast and then propagated eastward. Other vortices were also seen to propagate westward south of the Balearic Islands. The easternmost half of the basin is characterized by the presence of a well-defined anticlockwise circuit between $5^{\circ}$ and $9^{\circ} \mathrm{E}$ with a western central branch located at $38^{\circ} \mathrm{N}$. One eddy was observed to escape from the circuit and propagate westward south of the Balearic Islands. North of the Algerian Basin $\left(40^{\circ}-44^{\circ} \mathrm{N}, 2^{\circ} \mathrm{W}-10^{\circ} \mathrm{E}\right)$ only a few trajectories were found. This pattern had been already suggested in some previous papers (Fuda et al. 2000; Puillat et al. 2002; Salas et al. 2002), although here it emerges, in a clear way associated with our selection criterion and with an unexpected degree of detail. A look to the bathymetry of the region (see Fig. 1) suggests that bathymetry combined with the beta drift of vortices may be the dominant mechanisms for the open sea part of the circuit while, as previously suggested by Millot (1999), near the Algerian coast a current makes the vortices propagate to the east until the entrance of the Channel of Sardinia where they are forced to move to the north, constrained by the shallow bottom topography. It is interesting to appreciate how a vortex, after completing some loops around this circuit, finally escaped and propagated westward in close agreement with the monitoring of Advanced Very High Resolution Radiometer (AVHRR) images made by Puillat et al. (2002). Another clear pattern within the Algerian Basin is the existence of identified regions of vortex detachment from the coast around $4^{\circ}$ and $8^{\circ} \mathrm{E}$. This coincides with the results of Bouzinac et al. (1998) that, through an analysis using complex EOF, also identify the same detachment regions. The detachment region around $8^{\circ} \mathrm{E}$ is related to the bathymetric effect of the Sardinia Channel (Bouzinac et al. 1998). A
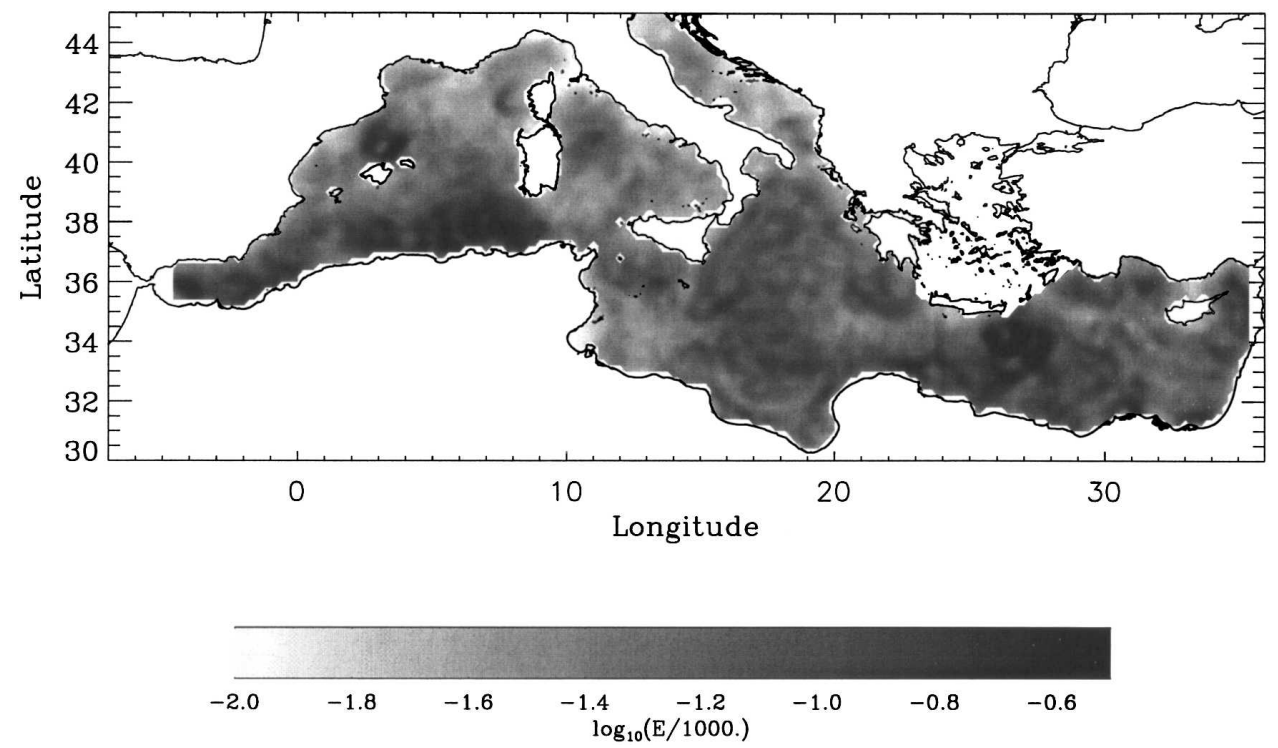

FIG. 11. Spatial distribution of eddy kinetic energy for the period October 1992-October 1999. 
possible mechanism to explain the detachment around $4^{\circ} \mathrm{E}$ could be the interaction with an additional anticyclonic vortex located to the east, close to the region where vortices from the circuit reach again the Algerian coast.

In the Eastern Mediterranean, Hamad et al. (2005) have analyzed the surface circulation using infrared imagery and found that Atlantic surface waters incoming from the Western Mediterranean can penetrate into the Ionian Sea in the form of mesoscale vortices that propagate usually southeastward, but subject to high seasonal and interannual variability (Pinardi et al. 1997; Poulain 1998; Manca et al. 2002) with branches even going northward. Similar characteristics are found in the trajectories presented here (Fig. 9) where there is no clearly prevailing direction downstream of the Strait of Sicily. Even some vortices appear to propagate westward around $20^{\circ} \mathrm{E}$. In the central Ionian Basin (Eastern Mediterranean Sea: $30^{\circ}-40^{\circ} \mathrm{N}, 10^{\circ} \mathrm{W}-22^{\circ} \mathrm{E}$ ) the propagation of vortices is to the southeast along an undulating imaginary line connecting Sicily and the east coast of Lybia. South of Pelops, one sees the undulating trajectories of some vortices that propagate westward. This path is located at the same latitude as other paths with the same orientation located close to the Sirte rise, which suggests that some Pelops vortices could reach this area. However, no vortex was observed to cross the Ionian Basin at this latitude. In other studies (Matteoda and Glenn 1996; Larnicol et al. 2002), as well as in Hamad et al. (2005), it has been observed that the Pelops vortex propagates westward. A detailed look at its trajectory (see Fig. 9) shows a wavy path that may be due to the interaction with the Hellenic trench and the Mid-Mediterranean Ridge (see Fig. 1). In the northern part of the Ionian, some vortex trajectories indicate a northward and then a southward motion, in a sort of meandering that has been described by several authors as an Atlantic-Ionian stream (Robinson et al. 1991; Robinson and Golnaraghi 1994; Malanotte-Rizzoli et al. 1997). To the south can be seen another imaginary line along which vortices tend to propagate. Close to the Libyan coast (longitude $15^{\circ} \mathrm{E}$ ) there were observed some eddies propagating northwestward following the coast. East of the Ionian Basin, close to the Cretan passage, vortices seem to propagate eastward parallel to the African coast. South of Crete, vortices are drifting mainly along the African coast, although some of them move either away from or toward the coast. Other characteristic and prominent features, also coincident with the observations of Hamad et al. (2005), are the propagation of vortices parallel to the Mid-Mediterranean Ridge, well-marked vortex trajectories in the Mersa-Matruth area surrounding the Herodotus abys- sal plain, the southward displacement of the Ierapetra vortex, and the westward propagation along the slope south of Anatolia.

Thus, from the above comparison with other observations we can be sure that intense anticyclonic vortices agree well with real reported vortices. The physical interpretation of weak vortices is more difficult. Results show that most vortices identified in SLA maps are weak vortices (about $80 \%$ ) that have predominantly small sizes, with low values of energy, and spread over the whole Mediterranean Sea. To interpret weak vortices, trajectories of vortices in the Algerian Basin have been visually inspected through the complete sequence of Okubo-Weiss maps without applying any threshold to vortex amplitudes. Results show that few vortices have amplitudes smaller than $2 \sigma_{W}$, although they were sometime labeled as intense vortices during their life. Furthermore, the detailed comparison with some of the aforementioned observations about specific tracked vortices shows that some small vortices, of just a few grid points, may be the end stages of intense vortices (Isern-Fontanet et al. 2003; Font et al. 2004). This suggests that part of the population of week vortices corresponds to low-energy states of initial or final stage intense vortices. The sensibility of the classification to the selected threshold value was explored by changing it in the range $1.5-2.5 \sigma_{W}$ without any significant difference. Although, other weak vortices do not fall in the above situation and can be identified as coherent vortices, they may be attributed to noise present in altimetric data, generated by the optimal interpolation scheme or by algorithms used for calculating geostrophic velocities and their derivatives.

Another important point to be discussed from the census here presented concerns the high proportion of cyclonic structures. Observations show that cyclonic vortex trajectories have less well defined patterns (Fig. 10) but prominent features are as follows: in the places of known semipermanent vortices, as in the Alboran Sea and Ierapetra vortex, trajectories of cyclonic vortices tend to be concentrated around almost the same points as intense anticyclonic vortices. Larnicol et al. (2002) have studied with great detail the temporal evolution of the Alboran vortices with the same dataset used in our study. It is clearly seen that the analysis of sea level measurements with respect to a mean implies that a permanent structure is seen as an anticyclonic structure half of the time and a cyclonic structure the other half, located always in the same position. A different case is in the region of the circuit of vortices previously described in the eastern part of the Algerian Basin, where the shape of trajectories suggests that cyclonic structures may follow also this circuit although 


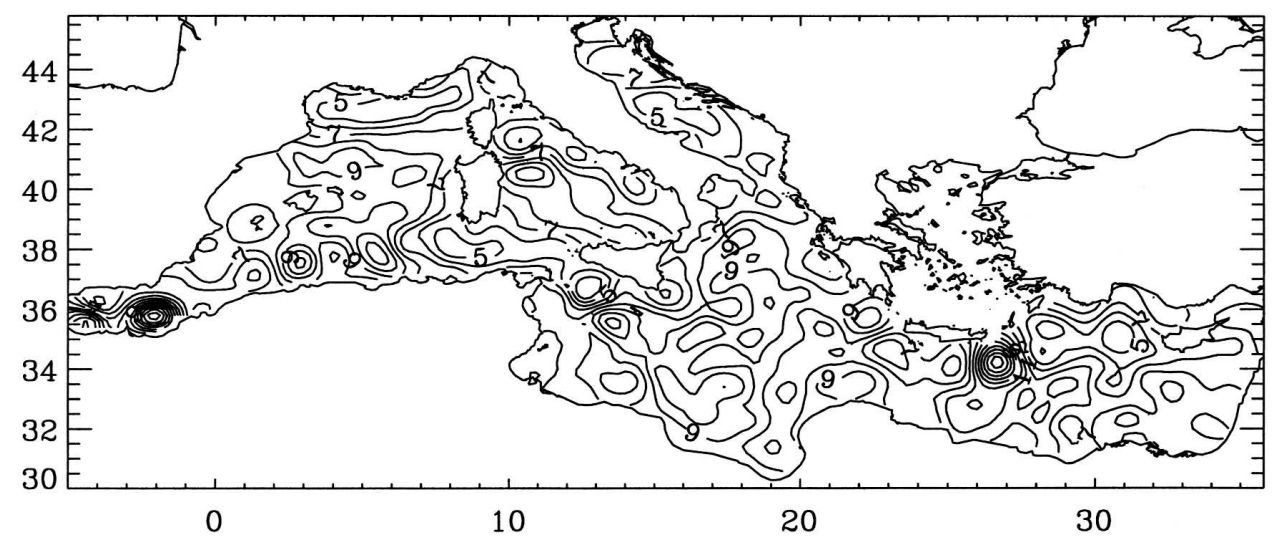

FIG. 12. Spatial distribution of amplitudes $\left(H_{0}\right)$ of the seasonal signal for the period October 1992-October 1999.

they are sharper than the anticyclonic. This points to the fact that some of such cyclonic structures are real vortices. However, we do not have a definitive answer to these questions and these structures will be investigated in future studies.

A final question to be discussed is the origin of the great amount of structures, anticyclonic and cyclonic, identified in the SLA maps. One point here could be the missing subtraction of the seasonal variability in the generation of interpolated maps and how it affects the census determination. To consider this we have fitted a seasonal function to each grid point in SLA maps given by

$h_{\mathrm{SE}}(x, y)=H_{0}(x, y) \sin \left\{\frac{2 \pi}{T}\left[t+t_{0}(x, y)\right]\right\}, T=365$ days.

Then the seasonal signal has been subtracted and the census recomputed; the results do not change significantly the statistical properties of the original census (not shown). However, the distribution of seasonal signal amplitudes $H_{0}$ allows us to shed light on the difference between quasi-permanent or transient structures (see Fig. 12). It can be seen that regions with high amplitudes of the seasonal signal correspond to the quasipermanent Alboran vortices and the Ierapetra vortex, also identified in the distribution of coherent vortices (Fig. 8). On the other hand, a transient vortex as seen in the Catalan Sea $\left(40.5^{\circ} \mathrm{N}, 3^{\circ} \mathrm{E}\right.$ : Pascual et al. 2001), apparent in Fig. 7, is less identifiable in Fig. 8 (represented by a few points) but cannot be observed in the distribution of $H_{0}$. A different case is the region close to the Algerian coast, around $4^{\circ} \mathrm{E}$, with a moderate seasonal signal that is also found in the distribution of vortex properties. However, in this case the seasonal signal should correspond with a local area where a vortex formed within the Algerian coastal current can detach from the coast (e.g., Puillat et al. 2002) and not with a semipermanent vortex structure.

Another element that could modify the census of vortices is the use of a mean dynamic topography. This modification may come through three main ways: First, since the construction of SLA requires the subtraction of the mean, it is expected that SLA may contain more structures associated with variations with respect to the mean; then the use of a mean dynamic topography should reduce their number unless it already contains structures, for example, due to its construction method. However, notice that in this paper we have proposed a selection criterion that helps to discard the structures not associated with coherent structures from SLA maps. A second modification of the census may come from the masking of the presence of vortices due to the inclusion of mean currents associated with the mean dynamic topography. This could happen for homogeneous mean flows or in flows with background vorticity but, as has been shown by Jeong and Hussain (1995), in such cases the Okubo-Weiss criterion is sufficiently robust to extract the embedded vortices because of its invariance under Galilean transformations. The third modification of the census built above may come from the fact that the addition of mean currents could modify vorticity and strain and thus the value of $\sigma_{W}$ used for the identification of vortices. This would modify the number of vortices identified but it is expected that coherent vortices would remain. Then, although the use of a mean dynamic topography may modify the census of vortices we do not expect that main oceanographic results would change because of the good agreement between the results presented here and independent observations. 


\section{Conclusions}

In previous sections we have shown how a criterion based on the Okubo-Weiss parameter allows one to detect and extract vorticity-dominated structures in the Mediterranean Sea from SLA maps. A census of these structures provides a way to get the main statistical properties of the vortices in the Mediteranean Sea. The cumulative distribution of such structures over the time series has revealed that they appear distributed over the entire domain. However, the statistical properties of the census of such structures suggest a categorization on the basis of their amplitude. Structures with $a>2 \sigma_{W}$ have been defined as intense coherent vortices (around $20 \%$ ) whose main characteristic is that they are distributed inhomogeneously in the domain. A tracking algorithm applied over the whole time series has provided a first global picture of their preferential paths showing complex but well-defined patterns. Some of them correspond to known quasi-steady features, such as the Alboran and Ierapetra gyres. Most of them appear as propagating structures in both basins, in some cases, with relatively long paths and circuits.

The physical interpretation of weak vortices $a<2 \sigma_{W}$ is more difficult. Results show that most $(80 \%)$ vortices identified in SLA maps are weak and have predominantly small sizes, low values of energy, and fill the whole Mediterranean Sea. A detailed comparison with previous observations of some specific tracked vortices suggests that a part of the population of weak vortices corresponds to low energy states of initially intense vortices. Probably the rest of weak vortices are associated with noise present in altimetric maps.

We therefore conclude that the intense coherent structures educed by our proposed criterion applied to Mediterranean SLA maps are consistent with independent observations of reported coherent vortices. The interest of our kinematical approach versus Eulerian statistics is that it is objectively and systematically applied to a magnitude directly linked to the ocean dynamics and results are interpreted in terms of the individual coherent structures that dominate the flow dynamics. In particular, it is clearly shown that for the Mediterranean Sea, the spatial distribution of most intense coherent vortices is highly correlated with the areas of high levels of eddy kinetic energy. This demonstrates the role of these structures as being the most important source of variability and that they constitute the most relevant dynamical patterns of the flow in the basin. It is learned from two-dimensional turbulence studies that coherent vortices play a key role in the dispersion of passive scalars because they drastically modify the probability density functions of the velocity field (Bracco et al. 2000a) and therefore they influence particle dispersion (Pasquero et al. 2001). Indeed, this result suggests that future studies of transport and mixing in the Mediterranean Sea should pay special attention to these dynamically relevant structures.

Acknowledgments. This is a contribution to the IMAGEN project funded by the Spanish $\mathrm{R}+\mathrm{D}$ Plan (REN2001-0802-C02-02) and MERSEA project funded by the European Union 6th Framework Program (AIP3-CT-2003-502885). Jordi Isern-Fontanet has been partially supported by contracts from IMAGEN and MERSEA projects. Altimetric maps for the period analyzed were elaborated and provided by CLS (Toulouse, France) under contract of the MATER project funded by the European Union MAST Program (MAS3-CT960051). We thank two anonymous reviewers for the comments that helped to improve this manuscript and acknowledge the help of John A. Young in the preparation of its final version.

\section{REFERENCES}

Andrade, C., and E. Barton, 2000: Eddy development and motion in the Caribbean Sea. J. Geophys. Res., 105 (C11), 2619126201.

Armi, L., D. Hebert, and N. Oakey, 1989: Two years in the life of a Mediterranean salt lens. J. Phys. Oceanogr., 19, 354-370.

Aviso, 1996: Aviso user handbook. Corrected sea surface height products. $2.0 \mathrm{ed}$. AVINT-011-311-CN, $21 \mathrm{pp}$.

Ayoub, N., P. Le Traon, and P. De Mey, 1998: A description of the Mediterranean surface variable circulation from combined ERS-1 and TOPEX/POSEIDON altimetric data. $J$. Mar. Syst., 18, 3-40.

Basdevant, C., and T. Philipovitch, 1994: On the validity of the "Weiss criterion" in two-dimensional turbulence. Physica D, 113, 17-30.

Bouzinac, C., J. Vázquez, and J. Font, 1998: CEOF analysis of ERS- 1 and TOPEX/POSEIDON combined altimetric data in the region of Algerian current. J. Geophys. Res., 103, 80598071.

Bracco, A., J. LaCasce, and A. Provenzale, 2000a: Velocity probability density functions for oceanic floats. J. Phys. Oceanogr., 20, 461-474.

,$- \ldots$ C. Pasquero, and A. Provenzale, 2000b: The velocity distribution of barotropic turbulence. Phys. Fluids, 12, 24782488.

Brasseur, P., J. M. Beckers, J. Brankart, and R. Shoenauen, 1996: Seasonal temperatures and salinity fields in the Mediterranean sea: Climatological analysis of a historical data set. Deep-Sea Res., 43, 159-192.

Brown, O., P. Cornillon, and S. Emmerson, 1986: Gulf string warm rings: A statistical study of their behavior. Deep-Sea Res., 33, 1459-1473.

Chassignet, E., 1992: Rings in numerical models of ocean general circulation: A statistical study. J. Geophys. Res., 97 (C6), 9479-9492.

Chong, M. S., A. E. Perry, and B. J. Cantwell, 1990: A general 
classification of three-dimensional flow field. Phys. Fluids, 2A, 765-777.

Davis, R., 1987: Modeling eddy transport of passive tracers. $J$. Mar. Res., 45, 635-666.

Elhmaïdi, D., A. Provenzale, and A. Babiano, 1993: Elementary topology of two-dimensional turbulence from a Lagrangian viewpoint and single-particle dispersion. J. Fluid Mech., 257, 533-558.

Farge, M., G. Pellegrino, and K. Schneider, 2001: Coherent vortex extraction in $3 \mathrm{~d}$ turbulent flows using orthogonal wavelets. Phys. Rev. Lett., 87, doi:10.1103/PhysRevLett.87.054501.

Flexas, M., X. Durrieu de Madron, M. A. Garcia, M. Canals, and P. A. Arnau, 2002: Flow variability in the Gulf of Lions during the mater hff experiment (March-May 1997). J. Mar. Syst., 33-34, 197-214.

Font, J., J. Isern-Fontanet, and J. Salas, 2004: Tracking a big anticyclonic eddy in the Algerian basin (western Mediterranean Sea). Sci. Mar., 68, 331-342.

Fuda, J., C. Millot, I. Taupier-Letage, U. Send, and J. Bocognano, 2000: XBT monitoring of a meridian section across the western Mediterranean Sea. Deep-Sea Res., 47, 2191-2218.

García-Gorriz, E., and J. Vázquez-Cuervo, 1999: Oceanatmosphere coupling in the Mediterranean sea from TOPEX/ Poseidon, ERS1 and AVHRR. Int. J. Remote Sens., 20, $2127-$ 2147.

Goni, G., and W. Johns, 2001: A census of North Brazil current rings observed from TOPEX/POSEIDON altimetry: 19921998. Geophys. Res. Lett., 28, 1-4.

Haller, G., 2005: An objective definition of a vortex. J. Fluid Mech., 525, 1-26.

Hamad, N., C. Millot, and I. Taupier-Letage, 2005: The surface circulation in the eastern basin of the Mediterranean sea. Progress in Oceanography, Vol. 66, Pergamon, 287-298.

Holland, C., and G. Mitchum, 2001: Propagation of Big Island eddies. J. Geophys. Res., 106, 935-944.

Holmes, P., J. L. Lumley, and G. Berkooz, 1996: Turbulence, Coherence Structures, Dynamical Systems and Symetry. Cambridge University Press, 438 pp.

Hooker, S., J. Brown, and A. Kirwan, 1995: Kinematics of warmcore dipole ring. J. Geophys. Res., 100, 24 797-24 809.

_ R. Ried, J. Brown, and A. Kirwan, 1997: Remote sensing of dipole rings. IEEE Trans. Geosci. Remote Sens., 35, 13941399.

Hua, B. L., and P. Klein, 1998: An exact criterion for the stirring properties of nearly two-dimensional turbulence. Physica D, 113, 98-110.

Hunt, J., A. Wray, and P. Moin, 1988: Eddies, stream, and convergence zones in turbulent flows. Center for Turbulence Research Rep. CTR-S88, 193 pp.

Isern-Fontanet, J., E. García-Ladona, and J. Font, 2003: Identification of marine eddies from altimetry. J. Atmos. Oceanic Technol., 20, 772-778.

_ J. J. Font, E. Garcia-Ladona, M. Emelianov, C. Millot, and I. Taupier-Letage, 2004: Spatial structure of anticyclonic eddies in the Algerian basin (Mediterranean Sea) analyzed using the Okubo-Weiss parameter. Deep-Sea Res., 51, 3009-3028.

Iudicone, D., R. Santoleri, S. Marullo, and P. Gerosa, 1998: Sea level variability and surface eddy characteristics in the Mediterranean Sea from TOPEX/POSEIDON data. J. Geophys. Res., 103, 2995-3011.
Jeong, J., and F. Hussain, 1995: On the identification of a vortex. J. Fluid Mech., 285, 69-94.

Jiménez, J., 1996: Algebraic probability density tails in decaying isotropic two-dimensional turbulence. J. Fluid Mech., 313, 223-240.

Kelly, K., and P. Strub, 1992: Comparison of velocity estimates from advanced very high resolution radiometer in the coastal transition zone. J. Geophys. Res., 97, 9653-9668.

Larnicol, G., P. Le Traon, N. Ayoub, and P. De Mey, 1995: Mean sea level and surface circulation variability of the Mediterranean Sea from 2 years of TOPEX/POSEIDON altimetry. $J$. Geophys. Res., 100 (C12), 385-396.

- N. Ayoub, and P. Le Traon, 2002: Major changes in the Mediterranean sea level variability from 7 years of TOPEX/ POSEIDON ERS-1/2 data. J. Mar. Syst., 33-34, 63-89.

La Violette, P. E., 1995: Seasonal and Interannual Variability of the Western Mediterranean Sea. Coastal and Estuarine Studies, Vol. 46, Amer. Geophys. Union, 373 pp.

Lentini, C., D. Olson, and G. Podestá, 2002: Statistics of Brazil Current rings observed from AVHRR: 1993 to 1998. Geophys. Res. Lett., 29, 1811, doi:10.1029/2002GL015221.

Le Traon, P., and F. Ogor, 1998: ERS-1/2 orbit improvement using TOPEX/POSEIDON: The $2 \mathrm{~cm}$ challenge. J. Geophys. Res., 103 (C4), 8045-8057.

—_, F. Nadal, and N. Ducet, 1998: An improved mapping method of multi-satellite altimeter data. J. Atmos. Oceanic Technol., 15, 522-534.

Malanotte-Rizzoli, P., and A. R. Robinson, 1994: Ocean Processes in Climate Dynamics: Global and Mediterranean Examples. NATO ASI Series C: Mathematical and Physical Sciences, Vol. 419, Kluwer Academic, 437 pp.

_ - and Coauthors, 1997: A synthesis of the Ionian Sea hydrography, circulation and water mass pathways during POEM phase I. Progress in Oceanography, Vol. 39, Pergamon, 153204.

Manca, B. B., L. Ursella, and P. Scarazzato, 2002: New development of Eastern Mediterranean circulation from thermohaline properties and marine current measurements. Mar. Ecol. P.S.Z.N., 23 (Suppl. 1), 237-257.

Matteoda, A., and S. M. Glenn, 1996: Observation of recurrent mesoscale eddies in the eastern Mediterranean. J. Geophys. Res., 101 (C9), 20 687-20 709.

McWilliams, J., 1984: The emergence of isolated coherent vortices in turbulent flow. J. Fluid Mech., 146, 21-43.

_ 1990: The vortices of two-dimensional turbulence. J. Fluid Mech., 219, 361-385.

— , and J. B. Weiss, 1994: Anisotropic geophysical vortices. Chaos, 4, 305-311.

— - - and I. Yavneh, 1999: The vortices of homogeneous geostrophic turbulence. J. Fluid Mech., 401, 1-26.

Meyers, S., and S. Basu, 1999: Eddies in the eastern Gulf of Alaska from TOPEX/POSEIDON altimetry. J. Geophys. Res., 104 (C6), 13 333-13 343.

Millot, C., 1987: Circulation in the Western Mediterranean Sea. Oceanol. Acta, 10, 143-149. , 1999: Circulation in the western Mediterranean sea. J. Mar. Syst., 20, 423-442.

Morrow, R., F. Birol, D. Griffin, and J. Sudre, 2004: Divergent pathways of cyclonic and anti-cyclonic ocean eddies. Geophys. Res. Lett., 31, L24311, doi:10.1029/2004GL020974.

Okubo, A., 1970: Horizontal dispersion of floatable particles in 
the vicinity of velocity singularities such as convergences. Deep-Sea Res., 17, 445-454.

Olson, D., 1991: Rings in the ocean. Annu. Rev. Earth Planet. Sci., 19, 283-311.

Parada, M., and M. Cantón, 1998: Sea surface temperature variability in the Alboran sea from satellite data. Int. J. Remote Sens., 19, 2439-2450.

Pascual, A., B. Buongiorno-Nardelli, G. Larnicol, M. Emelianov, and D. Gomis, 2001: A case of intense anticyclonic eddy in the Balearic sea (western Mediterranean). J. Geophys. Res., 107, 3183, 10.1029/2001JC000913.

Pasquero, C., A. Provenzale, and A. Babiano, 2001: Parametrization of dispersion in two-dimensional turbulence. J. Fluid Mech., 439, 279-303.

Picco, P., 1990: Climatological Atlas of the Western Mediterranean. ENEA, Rome, Italy, $224 \mathrm{pp}$.

Pinardi, N., G. Korres, A. Lascaratos, V. Roussenov, and E. Stanev, 1997: On the interannual variability of the Mediterranean Sea upper ocean circulation. Geophys. Res. Lett., 24, $425-427$.

Poulain, P. M., 1998: Lagrangian measurements of surface circulation in the Adriatic and Ionian Seas between November 1994 and March 1997. Rapp. Commun. Int. Mér Médit., 35, 190-191.

Press, W. H., S. A. Teukolsky, W. T. Vetterling, and B. P. Flannery, 1994: Numerical Recipes in FORTRAN: The Art of Scientific Computing. Cambridge University Press, 973 pp.

Provenzale, A., 1999: Transport by coherent barotropic vortices. Annu. Rev. Fluid Mech., 31, 55-93.

Puillat, I., I. Taupier-Letage, and C. Millot, 2002: Algerian eddies lifetime can near 3 years. J. Mar. Syst., 31, 245-259.

Rhines, P. B., 1979: Geostrophic turbulence. Annu. Rev. Fluid Mech., 11, 401-441.

Robinson, A., and M. Golnaraghi, 1994: The physical and dynamical oceanography of the Mediterranean Sea. Ocean Processes in Climate Dynamics: Global and Mediterranean Examples, P. Malanotte-Rizzoli and A. R. Robinson, Eds., NATO ASI Series C, Vol. 419, Kluwer Academic, 255-306.
— circulation: Features, structure and variability. Dyn. Atmos. Oceans, 15, 215-240.

Salas, J., C. Millot, J. Font, and E. García-Ladona, 2002: Analysis of mesoscale phenomena in the Algerian basin from drifting buoys and infrared images. Deep-Sea Res., 49, 245-266.

Salmon, R., 1998: Lectures on Geophysical Fluid Dynamics. Oxford University Press, $400 \mathrm{pp}$.

Schouten, M., P. de Ruijter, P. van Leeuwen, and J. Lutjeharms, 2000: Translation, decay and splitting of Agulhas rings in the southeastern Atlantic Ocean. J. Geophys. Res., 105 (C9), 21 913-21 925.

Siegel, A., and J. B. Weiss, 1997: A wavelet-packet census algorithm for calculating vortex statistics. Phys. Fluids, 7, 19881999.

Stammer, D., 1997: Global characteristics of ocean variability estimated from regional TOPEX/Poseidon altimeter measurements. J. Phys. Oceanogr., 27, 1743-1769.

Stocker, R., and J. Imberger, 2003: Horizontal transport and dispersion in the surface layer of a medium-sized lake. Limnol. Oceanogr., 48, 971-982.

Testor, P., and J.-C. Gascard, 2004: Large-scale flow separation and mesoscale eddy formation in Algerian basin. Progress in Oceanography, Vol. 66, Pergamon, 211-230.

Truesdell, C., 1953: The Kinematics of Vorticity. Indiana University Press, $232 \mathrm{pp}$

Vazquez-Cuervo, J., J. Font, and J. Martinez-Benjamin, 1996: Observations on the circulation in the Alboran Sea using ERS1 altimetry and sea surface temperature data. J. Phys. Oceanogr., 26, 1426-1439.

Viúdez, A., J. Tintoré, and R. L. Haney, 1996: Circulation in the Alboran Sea as determined by quasi-synoptic hydrographic observations. Part I: Three-dimensional structures of two anticyclonic gyres. J. Phys. Oceanogr., 26, 684-705.

Weiss, J., 1991: The dynamics of enstrophy transfer in twodimensional hydrodynamics. Physica D, 48, 273-294.

Wilkin, J., and R. Morrow, 1994: Eddy kinetic energy and momentum flux in the Southern Ocean: Comparisons of a global eddy-resolving model with altimeter, drifter and currentmeter data. J. Geophys. Res., 99 (C4), 7903-7916. 